\title{
Inteligência, Habilidades Sociais e Expectativas Acadêmicas no Desempenho de Estudantes Universitários
}

\author{
Intelligence, Social Skills and Academic Expectations \\ in University Students' Performance
}

\author{
Gil Gomes ${ }^{*}, a, b$ \& Adriana Benevides Soares ${ }^{b}$ \\ ${ }^{a}$ Instituto Brasileiro de Hipnose Aplicada, Rio de Janeiro, Rio de Janeiro, Brasil \\ $\&{ }^{b}$ Universidade Salgado de Oliveira, Rio de Janeiro, Rio de Janeiro, Brasil
}

\begin{abstract}
Resumo
O objetivo deste estudo foi avaliar as correlações entre inteligência, habilidades sociais e expectativas acadêmicas e seus impactos no desempenho acadêmico de estudantes universitários matriculados nos primeiro e segundo períodos de cursos universitários. A amostra foi composta de 196 estudantes, sendo 156 mulheres e 40 homens com idade entre 17 e 59 anos. Foram utilizados os testes de Raciocínio Abstrato (RA) da Bateria BPR-5; o Inventário de Habilidades Sociais (IHS-Del-Prette) e o Questionário de Envolvimento Acadêmico - versão expectativas (QEA). Os resultados identificaram correlação entre habilidades sociais, expectativas acadêmicas e desempenho acadêmico. No entanto, a inteligência não se correlacionou nem com desempenho acadêmico nem com habilidades sociais. Palavras-chave: Inteligência, habilidades sociais, expectativas acadêmicas, desempenho acadêmico, estudantes universitários.
\end{abstract}

\begin{abstract}
This study aimed to assess the variables that could affect academic performance by studying correlations between intelligence, social skills, and academic expectations and how such factors affect academic performance of university students in their first year in college. The sample consisted of 196 students (156 women and 40 men) aged from 17 to 59. Abstract Reasoning (BPR-5s) tests, the Social Skills Inventory (IHS-Del-Prette), and the Academic Involvement Questionnaire (AIQ) - Expectations version were used. Results showed there are correlations among social skills, academic expectations, and academic performance. Intelligence, however, was not related to academic performance neither to social skills.

Keywords: Intelligence, social skills, academic expectations, academic performance, university students.
\end{abstract}

No Brasil, os investimentos em educação são apontados como alternativa para a solução de problemas sociais e econômicos. A formação de profissionais especialistas que supram tanto a demanda do mercado de trabalho como sejam capazes de refletir acerca das questões pertinentes ao porvir do país faz parte dos objetivos traçados pelos agentes envolvidos na área de educação (Carrara \& Betetto, 2009). As famílias, as empresas privadas e o governo são agentes que investem no desenvolvimento sociocognitivo dos estudantes e têm perspectivas em relação ao retorno social e econômico do capital investido nos futuros profissionais (Fernandes \& Almeida, 2005).

Porém, segundo Nogueira (2011), o censo realizado pelo Ministério da Educação e Cultura (MEC), entre 2008 e 2009, demonstrou que 896.455 estudantes se evadiram

\footnotetext{
"Endereço para correspondência: Rua Barata Ribeiro, 399, Sala 202, Copacabana, RJ, Brasil 22231-090. E-mail: gil.gomes@globo.com
}

das universidades nesse período. Esse total representa um percentual de (20,9\%) dos alunos matriculados no Ensino Superior, sendo $114.173(10,5 \%)$ de universidades públicas e $782.282(24,5 \%)$ de universidades privadas. Para Hipólito (2011, citado por Nogueira, 2011), se for considerado que cada estudante custa, em média, $\mathrm{R} \$ 15.000,00$ (quinze mil reais) ao ano à universidade pública e $\mathrm{R} \$ 9.000,00$ (nove mil reais) ao ano às universidades privadas, a perda gira em torno de $\mathrm{R} \$ 9.000 .000 .000,00$ (nove bilhões de reais) ao ano.

Em face da expressividade desses números para a nossa sociedade, os investimentos em pesquisas na área de educação, cuja ênfase seja a adaptação e o desempenho acadêmico dos estudantes aos cursos universitários, tornam-se imprescindíveis para analisar as variáveis que tenham interferência direta nos referidos critérios desses estudantes em particular. A competência em utilizar os recursos pessoais e institucionais, principalmente na fase inicial do curso, pode despertar o sentimento de indepen- 
dência no estudante para atender as demandas presentes no contexto universitário, seguir ao encontro de suas metas de curto e de longo prazo, monitorar e avaliar sua trajetória, na maioria das vezes, por um ângulo mais favorável (Primi, Santos, \& Vendramini, 2002).

Segundo a pesquisa desenvolvida por Braga, Miranda-Pinto e Cardeal (1997), que buscava identificar as causas da evasão do curso de química da Universidade Federal de Minas Gerais, foi verificado que o desempenho acadêmico do estudante, ou seja, as médias das notas de avaliação, principalmente no primeiro período, eram um dos aspectos que mais pesavam em sua decisão de permanecer no curso escolhido até o seu término. O estudo apontou que os conflitos da transição do Ensino Médio para a universidade influem no desempenho acadêmico, portanto, a carência de boa formação, especialmente no Ensino Médio, resultava em quatro reprovações seguidas no primeiro período do Ensino Superior e, consequentemente, na desistência do curso.

Portanto o desempenho do estudante universitário despertou o interesse de pesquisadores que buscaram entender algumas variáveis que poderiam influenciá-lo. Alguns apontaram para a importância das expectativas acadêmicas (Almeida et al., 2003; Baptista, Amadio, Rodrigues, Santos, \& Palludetti, 2004; Fernandes \& Almeida 2005; Ferreira, Almeida, \& Soares, 2001; Igue, Bariani, \& Milanesi, 2008; Pascarella \& Terenzini 2005; Terenzini, Springer, Pascarella, \& Nora, 1995). Diversos verificaram o impacto das habilidades sociais (Bariani \& Pavani, 2008; Contreras, Caballero, Palácio, \& Pérez, 2008; Feitosa, Matos, Del Prette, \& Del Prette, 2009; Furtado, Falcone, \& Clark, 2003). Outros identificaram a conexão existente entre diversos aspectos de capacidades cognitivas e entre eles a inteligência fluida ( $g f$ ) (Almeida, Guisande, \& Primi, 2008; Primi et al., 2002; Primi et al., 2001).

Em relação às expectativas acadêmicas, o ingresso ao Ensino Superior elicia níveis elevados de expectativas relacionadas ao futuro e aos desafios com que os alunos irão se defrontar na universidade. O universitário pode amoldar suas expectativas ou se frustrar, porém o resultado depende de recursos para seu ajuste ao novo contexto escolar. $\mathrm{Na}$ tentativa de obter resultados favoráveis no meio acadêmico, o aluno, ao permanecer na universidade, passa por transformações cognitivas, emocionais e comportamentais, desde a inserção na universidade até os períodos finais do curso. Para os estudantes, as mudanças acontecem e são reforçadas mutuamente, além disso, abrangem alterações tanto cognitivas e psicossociais como atitudes, valores e progresso moral. Portanto, os calouros que vencem as dificuldades dos períodos iniciais de adaptação, no decorrer da graduação experimentam modificações em seu senso crítico e em sua maneira de pensar, ou seja, os alunos que concluem o curso tornam-se pensadores mais sofisticados a respeito do mundo em que estão envolvidos (Pascarella \& Terenzini, 2005).

As expectativas em relação ao ingresso à universidade podem interferir na transição do aluno do Ensino Médio para o Ensino Superior o que significa dizer que, quanto maior o nível de expectativas existirem, maiores são as inferências do estudante geradas por estas. O que pode resultar em ações focadas no desempenho acadêmico e, por conseguinte, na percepção de um ambiente reforçador de pensamentos, sentimentos e comportamentos que inibem, limitam ou facilitam a adaptação ao novo meio social (Fernandes \& Almeida, 2005).

As expectativas são as predições que a pessoa faz em relação ao seu desempenho em um determinado contexto social para atender não só as suas necessidades como as do outro. As expectativas induzem a pessoa a selecionar suas ações dentre a variedade de repertórios de habilidades que possui para corresponder satisfatoriamente às demandas pessoais e sociais contextualizadas. No entanto, pode ser possível que as expectativas do estudante não estejam necessariamente alinhadas com as demandas objetivas e sim com as demandas subjetivas. Nesse caso, a realidade material deixa de ser o causador crítico da situação e cede espaço à realidade individual (Caballo, 2003).

A pesquisa realizada por Cunha e Carrilho (2005), sobre o processo de adaptação ao Ensino Superior e o rendimento acadêmico com 100 alunos ingressantes à universidade, indicou que um ambiente universitário ajustado e acolhedor poderia auxiliar no desenvolvimento e utilização dos potenciais pessoais dos alunos recém-chegados. Para esses autores, além do apoio institucional compatível à adaptação e ao rendimento acadêmico, a atuação do aluno no ambiente universitário também é um fator associado ao seu desempenho, que acontecerá de acordo com as suas características psicológicas. Esses mesmos estudiosos ressaltaram a dinâmica existente nesse contexto entre recursos pessoais e institucionais, os quais interagem simultaneamente e interferem no desempenho do estudante alterando sua percepção de bem-estar físico e psicológico.

O estudo de Igue et al. (2008) com 203 alunos de Psicologia do $1^{\circ}$ e $5^{\circ}$ ano de uma universidade em São Paulo, sobre expectativas e vivências acadêmicas averiguou que, na dimensão institucional, embora os estudantes identificassem, pouco exploravam os serviços oferecidos pela instituição de ensino. Além disso, suas expectativas oscilavam conforme o ano de estudo cursado. Para o aluno iniciante, relegar os recursos fornecidos pela instituição, talvez, signifique a falta de um programa que integre o aluno ao ambiente acadêmico enquanto que para o concluinte represente mero conformismo com os recursos conhecidos e que já usufruem dentro do campus. $\mathrm{O}$ estudo elucidou que $23,3 \%$ dos alunos do $1^{\circ}$ ano apresentaram expectativas "muito altas" e 49,5\% possuíam "expectativas altas" nas dimensões institucionais e pessoais. Os autores enfatizaram a importância do apoio adequado da instituição para o aluno aprender a ajustar suas expectações em conformidade à realidade dos recursos disponibilizados para dar suporte as suas necessidades no decurso do Ensino Superior. Em relação à dimensão pessoal, a pesquisa observou que os alunos que se percebem de maneira negativa, conside- 
ram-se menos capazes de se concentrar nas tarefas durante muito tempo, ficam ansiosos e apresentam frequentes flutuações de humor, o que poderia ser justificado pelo momento de transição que atravessam, quando iniciantes, e pelos desafios subjacentes aos trabalhos necessários para o término bem-sucedido do curso, quando concluintes.

Fernandes e Almeida (2005) realizaram um estudo com 68 alunos do primeiro ano da Universidade do Minho, em Portugal. Os referidos autores concluíram que, as expectativas criadas pelo estudante relativas aos recursos ambientais nos primeiros períodos abarcam desde relações sociais e interpessoais, material didático e biblioteca até trabalhar em pesquisas com professores e participar de atividades que auxiliem o seu desempenho na instituição. Os mesmos autores verificaram que estudantes que mantêm níveis de expectativas que vão ao encontro de seus recursos pessoais, frequentemente, atingem melhores índices de desempenho acadêmico. Por outro lado, observou-se também que os alunos com baixo rendimento acadêmico criavam expectativas mais distantes de seu potencial e buscavam de maneira distorcida obter sucesso nos trabalhos com os professores, na manutenção de relacionamentos mais próximos com os colegas e nos recursos disponibilizados pela instituição de ensino. Assim, os estudantes com baixo rendimento inferiam, por exemplo, que as relações sociais mais próximas com os colegas universitários em atividades extracurriculares e o envolvimento em atividades com os professores seriam suficientes para alcançarem resultados condizentes com o que esperavam ao ingressar no Ensino Superior e, por consequência, dedicavam menos tempo ao estudo extraclasse.

A busca de desempenho acadêmico satisfatório por parte dos estudantes nos primeiros anos do Ensino Superior pode resultar em expectativas voltadas para as demandas que vão se deparar. Dentro desse conjunto de expectativas, podem surgir algumas distorcidas da realidade e românticas e com isso, se tornam disfuncionais aos objetivos traçados pelo estudante (Miller, 2005). Nesse sentido, várias pesquisas voltadas para expectativas acadêmicas apontam para expectativas altas dos estudantes iniciantes sobre as relações sociais e interpessoais, com professores e outros estudantes, como meio importante para o seu desempenho acadêmico adequado (Cunha \& Carrilho, 2005; Fernandes \& Almeida, 2005; Ferreira et al., 2001; Igue et al., 2008).

A capacidade de refletir hipoteticamente habilita o estudante a criar e considerar situações, que podem ser sociais e interpessoais, vislumbrando a probabilidade de estar preparado para atendê-las. Dessa maneira, o estudante é capaz de manter um cenário em mente, interagir mentalmente com os outros e determinar desenlaces alternados. A habilidade de desenhar o futuro pode levar a pessoa a assumir projetos mais ambiciosos e a direcionar comportamentos para o objetivo pensado. Assim, a capacidade de imaginar além dos limites convencionais traz um senso simples do ideal que entra em conflito com a realidade apresentada (Haward, 2005).
Dessa forma, para adequar as expectativas sobre as relações sociais e interpessoais e atender de maneira apropriada as demandas sociais e interpessoais fruto do ambiente universitário o aluno precisa ter habilidades sociais (Del Prette \& Del Prette, 2001a). As habilidades sociais são um conjunto de capacidades cognitivas e comportamentais que permitem a pessoa atender demandas sociais e interpessoais em um determinado contexto social. A qualidade das interações sociais e interpessoais podem se constituir numa oportunidade para o alcance dos objetivos institucionais, para o aperfeiçoamento das práticas educativas e para facilitar a conquista de diversificadas metas sociais e pessoais. Principalmente, as habilidades assertivas e as de enfrentamento que necessitam serem desenvolvidas em conjunto no ambiente acadêmico, com destaque para as habilidades de liderar, convencer, discordar, pedir mudanças de comportamento, expressar sentimento negativo, lidar com críticas, questionar, negociar decisões e resolver problemas. Entre as habilidades imprescindíveis ao desenvolvimento e as que podem auxiliar o estudante durante a sua vida acadêmica e fundamentais em sala de aula estão prestar atenção, seguir instruções, fazer e responder perguntas, oferecer e pedir ajuda a outra pessoa, agradecer, expor opiniões, discordar, controlar a própria raiva ou tédio e defender-se de acusações injustas (Caballo, 2003; Del Prette \& Del Prette, 1999; Del Prette \& Del Prette, 2001a).

O repertório de habilidades sociais restritos a sala de aula são fundamentais para o bom desempenho do estudante. A falta dessas habilidades pode se ater ao processo de aprendizagem, principalmente, as necessárias para realização de trabalhos que envolvam cooperação mútua e exposição oral de tarefas em sala de aula. Assim, aqueles estudantes que apresentarem baixo repertório de habilidades sociais para realização dessas atividades consequentemente terão o seu aprendizado prejudicado e poderão apresentar desempenho acadêmico incompatível com as suas expectativas (Bremer \& Smith, 2004).

Nesse sentido, Contreras et al. (2008), através de pesquisa que envolvia autorelato de 38 estudantes do $1^{\circ}$ ano do curso de psicologia, que faziam parte de um programa exclusivo para alunos com baixo rendimento acadêmico, da universidade de Barranquilla, apuraram que a falta de habilidades sociais para falar em público foi apontada por $29 \%$ do grupo pesquisado como uma das causas para os seus baixos rendimentos acadêmicos.

A pesquisa de Feitosa et al. (2009), sobre habilidades sociais e desempenho acadêmico verificou que os alunos capazes de obter melhores resultados são os que também conseguem construir relações sociais consistentes e, com isso, consideram-se mais aceitos pelos seus pares. Assim, os alunos com repertórios mais amplos de habilidades sociais se veem mais apoiados pelos colegas e, por extensão, sentem-se competentes em empregar recursos pessoais para equilibrar as relações sociais e interpessoais emergentes no contexto acadêmico e também para alimentar uma troca recíproca entre o estudante, o professor e o meio universitário. 
Gomes, G. \& Soares, A. B. (2013). Inteligência, Habilidades Sociais e Expectativas Acadêmicas no Desempenho de Estudantes Universitários.

O estudo de Furtado et al. (2003), com 178 estudantes de medicina do primeiro ao sexto ano, que objetivava verificar o impacto do estresse e das habilidades sociais na experiência acadêmica de estudantes abalizam que a falta de habilidades sociais dos alunos para enfrentar as situações interpessoais sociais que eles percebem como de risco social, está relacionado ao estresse e, dessa forma, traz preocupações quanto ao desempenho, a saúde e o bem estar psicossocial do universitário.

A pesquisa envolvendo relações interpessoais intrínsecas a sala de aula como espaço de relações interpessoais e de participação acadêmica (Bariani \& Pavani, 2008) coletaram informações de 21 professores e 90 alunos e listaram alguns motivos capazes de induzirem os estudantes universitários a participar ou não da aula. Dentre estes, a pesquisa identificou a dificuldade comportamental que foi dividida em categorias e entre as mais votadas está o comportamento individual do aluno e o do professor, que por sua vez, dá origem a subcategorias relação professor/ aluno, sinalizando para a importância do relacionamento interpessoal adequado entre alunos, e entre alunos e o professor como um dos fatores responsáveis para um profícuo desempenho acadêmico.

A comunicação no contexto acadêmico social é considerada dinâmica e se modifica amplamente para se ajustar a culturas variadas, não obstante, a diversas características demográficas e a regras estabelecidas pelos grupos e subgrupos de estudantes. Assim, para que uma resposta social seja avaliada como competente, teria que ser a consequência de uma série de condutas, que se iniciaria pela recepção exata dos estímulos interpessoais relevantes, se desdobraria em seu processamento flexível para gerar e avaliar as possibilidades de respostas, entre elas se escolheria a melhor, e culminaria com a manifestação apropriada ou apresentação da opção escolhida (Caballo, 2003).

$\mathrm{O}$ desempenho acadêmico satisfatório no Ensino Superior, implica na capacidade de interpretar racionalmente os desafios e, na maioria das vezes, modificar as crenças cristalizadas sobre eles. Esse processamento pode resultar na utilização dos recursos pessoais, sociais e institucionais adequados para tomada de decisão (Caballo, 2003; Haward, 2005). Para isso, o estudante universitário, em particular o iniciante, precisaria, em variadas tarefas, construir conceitos abstratos e derivar sugestões lógicas a partir de regras gerais para as quais ele teria poucos conhecimentos já memorizados sobre elas. Tal capacidade cognitiva estaria conectada a inteligência fluida ( $g f$ ) que poderia ter influência direta na resolução de problemas mais complexos, que levem o estudante a desenvolver a capacidade de reflexão e crítica, propostos nas avaliações disciplinares pelo corpo docente (Almeida, Ferreira, \& Guisande, 2009).

A relação da inteligência com o desempenho acadêmico foi estudada por Primi et al. (2002), em 960 estudantes universitários ingressantes e foi identificado que as correlações verificadas assinalam que o desempenho acadêmico encontra-se conexo a diversos perfis de capacidades cognitivas. A pesquisa demonstrou que o desempenho dos estudantes nos cursos de Medicina, Engenharia Civil, Matemática Psicologia e Administração, sofrem influencias da $g f$.

O estudo de Flores e Lever (2008), que envolveu 240 alunos mexicanos iniciantes do curso de Psicologia pode verificar que os estudantes entre os com melhores desempenhos acadêmicos no primeiro ano de faculdade estavam os que obtiveram maiores médias em raciocínio matemático, ou seja, associados a $g f$.

Em estudo que envolvia a $g f$ direcionada à inteligência no contexto acadêmico (Almeida et al., 2008), com 4.899 estudantes entre o $5^{\circ}$ e o $12^{\circ}$ ano de escolaridade em Portugal, em que utilizaram a Bateria de Provas de Raciocínio: versão PBR 5/6, versão BPR 7/9 e versão BPR 10/12, concluiu-se que há correlação moderada, e estatisticamente significativa, entre os testes de inteligência e as medidas acadêmicas, porém, sinalizaram que esta associação enfraquece à proporção que os alunos prosseguem nos níveis escolares. Indicaram também que nessa fase há interesses acadêmicos distantes entre os alunos, provavelmente por encontrarem-se voltados para conteúdos curriculares vocacionais.

O presente estudo visa identificar através de uma pesquisa quantitativa, se há correlação entre expectativas acadêmicas, habilidades sociais e $g f$ e qual o impacto desses três construtos no desempenho acadêmico do estudante no primeiro ano de faculdade, que foi medido através da média de suas notas de avaliação no final de cada período cursado, que é conhecido como coeficiente de rendimento $(\mathrm{CR})$.

\section{Método}

\section{Participantes}

A amostra foi composta por 196 estudantes universitários, com idade entre 17 e 59 anos, sendo 156 do sexo feminino e 40 do sexo masculino, devidamente matriculados no primeiro ou segundo períodos dos cursos superiores (ambos os períodos do primeiro ano de graduação), 19 eram do primeiro período e 177 do segundo, 35 pertencentes a classe social alta, 62 a classe social média e 99 a classe social baixa, 18 estudavam em instituição de ensino pública e 178 em instituição privada, 75 da área de humanas, 43 da área de saúde e 78 da área de educação.

\section{Instrumentos}

Teste de Raciocínio Abstrato da Bateria de Provas de Raciocínio (BPR-5; Almeida \& Primi, 2000). A BPR-5 é composta por duas formas (A e B) com cinco subtestes cada, porém para esta pesquisa foi utilizada somente a prova de Raciocínio Abstrato (RA) na forma $\mathrm{B}$, que foi validada para estudantes do $2^{\circ} \mathrm{e} 3^{\circ}$ anos do Ensino Médio. A prova de raciocínio abstrato é formada de 25 itens, sendo que 19 são comuns às formas A e B, de conteúdo abstrato, envolvem analogia de conteúdos de figuras geométricas. É necessária a descoberta da relação existente 
entre os dois primeiros termos e aplicá-la ao terceiro e, com isso, identificar o quarto termo entre as cinco opções de respostas. O tempo limite consiste de doze minutos e sua aplicação pode ser feita de forma coletiva. A consistência interna (Alpha de Cronbach) do Teste de raciocínio abstrato foi de 0,83 .

Inventário de Habilidades Sociais (IHS; Del Prette \& Del Prette, 2001b). Considera o repertório de habilidades sociais fundamentado na avaliação que a pessoa faz da constância com que reage às situações indicadas pelos 38 itens que formam o IHS. Composto do caderno de perguntas e da folha de respostas, o IHS contém instruções que sugerem ao avaliado fazer uma estimativa da frequência com que reagiriam às situações de interações sociais descritas no caderno de perguntas. Leva em conta o número de vezes que passou por tal situação. É sugerido que o participante siga uma escala do tipo Likert que varia de 0 - nunca ou raramente (em cada dez situações desse tipo, reajo dessa forma no máximo duas vezes) a 4 - sempre ou quase sempre (em cada dez situações desse tipo, reajo dessa forma 9 a 10 vezes). Dessa forma, $\mathrm{o}$ avaliado marca a frequência com que reagiria à forma apresentada em cada um dos itens. A aplicação pode ser feita de forma individual ou coletiva e avalia cinco fatores: (a) enfrentamento e autoafirmação com risco - composto por onze itens que remetem a situações interpessoais que levam o respondente a reagir pela afirmação e defesa de direitos e autoestima, com risco potencial de reação indesejável $(\alpha=0,96)$; (b) autoafirmação na expressão de afeto positivo - composto por sete itens que apontam demandas interpessoais de expressão de afeto positivo e de afirmação de autoestima, possibilitando risco mínimo de situação indesejável $(\alpha=0,86)$; (c) habilidades de conversação e desenvoltura social - formado também por sete itens que encerram a capacidade de lidar com situações sociais neutras, com um risco mínimo de reação indesejável pelo outro $(\alpha=0,81)$; (d) habilidades de autoexposição a desconhecidos ou a situações novas - composto por quatro itens que envolvem pequeno risco de reação indesejável do interlocutor $(\alpha=0,75)$; (e) habilidades de autocontrole da agressividade - composto por três itens que remetem a situações adversas com razoável controle da raiva e da agressividade $(\alpha=0,74)$.

$\mathrm{Na}$ análise de consistência interna do IHS foi obtido um coeficiente $\alpha=0,75$ para a escala total que pode ser considerado satisfatório, de acordo com a meta-análise de Petterson (1994, citado em Del Prette \& Del Prette, 2001b), permitindo assim, atribuir validade de construto. Com o objetivo de minimizar a tendência de adequação das respostas ao senso comum como respostas cabíveis pelo participante, 15 dos 38 itens foram elaborados com fraseados negativos, ou seja, a reação sugerida remete à falta de habilidades sociais. Nesses quinze itens, os pesos atribuídos as respostas são elaborados de maneira inversa, ou seja, de 4 para 0.

Questionário de Envolvimento Acadêmico (QEA; Versão A - Expectativas; Soares \& Almeida, 2007). Compõe-se de 38 questões subdivididas em cinco escalas relativas ao que o estudante espera da universidade. A escala vai de 1 (nunca ou quase nunca tem essa expectativa) até 4 (sempre ou quase sempre tem essa expectativa). As subescalas do QEA (versão A - Expectativas) distribuem-se da seguinte forma com seus respectivos Alphas de Cronbach: subescala envolvimento institucional composta por dez itens ( $\alpha$ $=0,83$ ), subescala envolvimento vocacional constituída por dez itens $(\alpha=0,79)$, subescala utilização de recursos organizada com seis itens $(\alpha=0,74)$, subescala envolvimento social ordenada também por seis itens $(\alpha=0,68)$, subescala envolvimento curricular estruturada por seis itens $(\alpha$ $=0,66)$. Na análise de consistência interna do QEA total foi obtido um coeficiente $(\alpha=0,83)$. Para a amostra deste estudo foram encontrados os seguintes Alpha de Cronbach: Envolvimento institucional, $\alpha=0,75$; Envolvimento vocacional, $\alpha=0,77$; Utilização de recursos, $\alpha=0,70$; Envolvimento social, $\alpha=0,55$; Envolvimento curricular, $\alpha=0,30$ e QEA Total: $\alpha=0,83$.

Este instrumento foi adaptado linguisticamente para o português do Brasil; foram substituídas palavras e expressões tipicamente utilizadas em Portugal, mas não usadas no Brasil por palavras correspondentes em português brasileiro.

\section{Procedimentos}

Os dados foram coletados nas faculdades e universidades que ofereciam cursos regulares, para isso foi solicitado um termo de autorização da universidade e dos participantes. Os dados foram coletados em grupos de no máximo 30 alunos por vez, e esses receberam instruções específicas para cada instrumento utilizado no estudo.

Com o objetivo de documentar as Diretrizes e Normas Regulamentadoras de pesquisa envolvendo seres humanos, dispostos na resolução 196/96 do Conselho Nacional de Saúde (CNS), o presente projeto foi encaminhado e aprovado pelo Comitê de Ética em Pesquisa da Universidade Salgado de Oliveira (UNIVERSO), parecer nº123/2010. Aos participantes desse projeto foi solicitada a assinatura do Termo de Consentimento Livre e Esclarecido.

\section{Resultados}

Para analisar as relações entre os construtos foram realizadas correlações (Pearson) entre os fatores dos instrumentos e entre os instrumentos. Além disso, fizeram-se análises de regressão linear múltipla para investigar a relação entre as variáveis independentes (inteligência, habilidades sociais e expectativas acadêmicas) e a variável dependente (desempenho acadêmico).

$\mathrm{Na}$ Tabela 1 são apresentados os valores de média e de desvio padrão dos resultados obtidos pela amostra nas variáveis em estudo.

A Tabela 2 apresenta os resultados da análise bivariada Pearson entre os escores de Inteligência, Habilidades Sociais, Expectativas Acadêmicas e Desempenho Acadêmico dos alunos (CR). 
Gomes, G. \& Soares, A. B. (2013). Inteligência, Habilidades Sociais e Expectativas Acadêmicas no Desempenho de Estudantes Universitários.

Tabela 1

Análise Descritiva das Variáveis Contínuas

\begin{tabular}{lccccc}
\hline \multicolumn{1}{c}{ Variáveis } & $N$ & Média & Desvio Padrão & Mínimo & Máximo \\
\hline Coeficiente de Rendimento & 191 & 8,39 & 1,10 & 4,50 & 10,00 \\
Envolvimento Institucional & 196 & 2,12 & 0,57 & 1,00 & 3,70 \\
Envolvimento Vocacional & 196 & 2,93 & 0,53 & 1,70 & 4,00 \\
Utilização de Recursos & 196 & 2,34 & 0,65 & 1,00 & 4,00 \\
Envolvimento Social & 196 & 2,69 & 0,57 & 1,17 & 4,00 \\
Envolvimento Curricular & 196 & 2,94 & 0,45 & 1,67 & 4,00 \\
QEA: Total & 196 & 2,61 & 0,37 & 1,65 & 3,75 \\
Inteligência: Total & 197 & 15,14 & 4,95 & 0,00 & 24,00 \\
IHS: Fator1- Enfrentamento & 195 & 10,17 & 3,05 & 2,99 & 17,89 \\
IHS: Fator2- Autoafirmação & 195 & 8,93 & 2,22 & 3,04 & 11,70 \\
IHS: Fator3- Conversação & 195 & 6,50 & 2,02 & 0,69 & 10,72 \\
IHS: Fator4- Autoexposição & 195 & 3,21 & 1,18 & 0,30 & 5,82 \\
IHS: Fator5- Autocontrole & 195 & 2,97 & 0,83 & 0,67 & 4,20 \\
IHS: Total & 195 & 31,73 & 5,99 & 19,15 & 45,38 \\
\hline
\end{tabular}

Tabela 2

Correlações entre Escores de Inteligência, Habilidades Sociais, Expectativas Acadêmicas e Desempenho

\begin{tabular}{lrr}
\hline \multicolumn{1}{c}{ Variáveis } & \multicolumn{2}{c}{ CR } \\
\cline { 2 - 3 } & $r$ & 0,890 \\
\hline Inteligência_Total (BPR5) & 0,01 & 0,007 \\
IHS: Fator 1- Enfrentamento & 0,19 & $<0,001$ \\
IHS: Fator 2- Autoafirmação & 0,38 & 0,002 \\
IHS: Fator 3- Conversação & $-0,22$ & 0,204 \\
IHS: Fator 4- Autoexposição & $-0,09$ & 0,011 \\
IHS: Fator 5- Autocontrole & 0,18 & 0,017 \\
IHS: Total & 0,17 & $<0,001$ \\
Envolvimento Institucional & $-0,27$ & 0,003 \\
Envolvimento Vocacional & 0,21 & $<0,001$ \\
Utilização de Recursos & $-0,30$ & 0,280 \\
Envolvimento Social & $-0,07$ & 0,048 \\
Envolvimento Curricular & 0,14 & 0,098 \\
QEA - Total & $-0,12$ &
\end{tabular}

A Tabela 2 mostra que quanto maior o escore no Fator 1 (Enfrentamento), Fator 2 (Autoafirmação), Fator 5 (Autocontrole) maior o desempenho acadêmico. Em geral, quanto maior o escore de habilidades sociais (IHS - Total) maior o desempenho acadêmico. O Fator 3 (Conversação) apresentou correlação negativa significativa com o desempenho acadêmico.

A Tabela 2 mostra que quanto maior o escore no Fator "Envolvimento Institucional" e "Utilização de Recursos", menor o desempenho acadêmico. Já o Fator 
Psicologia: Reflexão e Crítica, 26(4), 780-789.

"Envolvimento Vocacional" e o Fator "Envolvimento Curricular", apresentaram correlação positiva significativa com o desempenho acadêmico. O fator "Envolvimento Curricular" apresentou correlação positiva significativa com a inteligência.

Tabela 3

Correlação entre Expectativas Acadêmicas e Habilidades Sociais

\begin{tabular}{lcccccc}
\hline Variáveis & Enfrentamento & Autoafirmação & Conversação & Autoexposição & Autocontrole & IHS-Total \\
\cline { 2 - 7 } & $r$ & $r$ & $r$ & $r$ & $r$ & $r$ \\
\hline QEA: Env. Institucional & 0,07 & $-0,28^{* *}$ & 0,07 & $0,16^{*}$ & $-0,06$ & $-0,02$ \\
QEA: Env. Vocacional & $0,22^{* *}$ & $0,43^{* *}$ & $-0,01$ & 0,10 & $0,19^{* *}$ & $0,31^{* *}$ \\
QEA: Utili. de Recursos & $-0,00$ & $-0,19^{* *}$ & 0,11 & $0,15^{*}$ & $-0,18^{*}$ & $-0,03$ \\
QEA: Env. Social & 0,06 & 0,11 & 0,13 & $0,14^{*}$ & 0,07 & $0,15^{*}$ \\
QEA: Env. Curricular & 0,11 & $0,28^{* *}$ & 0,02 & 0,07 & 0,07 & $0,19^{* *}$ \\
QEA: Total & 0,13 & 0,07 & 0,10 & $0,19^{* *}$ & 0,01 & $0,17^{*}$ \\
\hline
\end{tabular}

Nota. * Significativo ao nível de 0,$05 ;$ ** Significativo ao nível de 0,01 .

Os resultados da Tabela 3 apontam que o Fator "Enfrentamento" apresentou correlação positiva significativa com o fator "Envolvimento Vocacional". O Fator "Autoafirmação" apresentou correlação negativa significativa com os fatores "Envolvimento Institucional", "Utilização de Recursos" e apresentou correlação positiva significativa com os fatores "Envolvimento Vocacional" e "Envolvimento Curricular". O Fator "Autoexposição" apresentou correlação positiva significativa com os fatores "Envolvimento Institucional", "Utilização de Recursos", "Envolvimento Social" e "QEA-Total".

O Fator "Autocontrole" apresentou correlação negativa significativa com o fator "Utilização de Recursos" e apresentou correlação positiva significativa com o fator "Envolvimento Vocacional". O "IHS-Total" apresentou correlação positiva significativa com os fatores "Envolvimento Vocacional", "Envolvimento Social", "Envolvimento Curricular" e o "QEA-Total". Como podemos observar nas Tabelas anteriores $2 \mathrm{e} 3$, as habilidades sociais se mostraram bem correlacionadas com as expectativas acadêmicas enquanto a inteligência só apresentou correlação com fator de expectativa acadêmica "Envolvimento Curricular".

Após avaliar a correlação entre as variáveis, procedeu-se a avaliação de modelos de regressão linear múltipla. No primeiro modelo foram escolhidas como variáveis independentes (preditoras) o escore total do IHS, o escore total do QEA e o resultado do BPR-5 (Inteligência). A variável dependente foi o desempenho acadêmico, mensurado pelo coeficiente de rendimento (CR). Adotou-se a técnica Stepwise Forward para escolha do melhor modelo. Nesta técnica as variáveis são incluídas no modelo uma a uma, por etapas, permanecendo apenas aquelas que são significativas e propiciam uma melhor explicação do modelo $\left(R^{2}\right)$. Na primeira etapa foi incluída a variável IHS-Total, sendo o modelo significativo com $R^{2}=0,030$. $\mathrm{Na}$ segunda etapa foi adicionada a variável QEA-Total, o que proporcionou um aumento significativo de 0,022 no $R^{2}$. A variável "Inteligência-Total" não foi incluída por não apresentar significância estatística no modelo. Assim o modelo final pode ser observado na Tabela 4.

Tabela 4

Modelo 1 - Expectativas Acadêmicas e Habilidades Sociais como Preditores do Desempenho Acadêmico (CR)

\begin{tabular}{lcccc}
\hline Modelo & \multicolumn{2}{c}{ Coeficientes } & $t$ & $p$ \\
\cline { 2 - 5 } & $B$ & Erro Padrão & & \\
\hline Constante & 8,40 & 0,65 & 12,86 & 0,001 \\
IHS: Total & 0,03 & 0,01 & 2,75 & 0,007 \\
QEA: Total & $-0,45$ & 0,21 & $-2,08$ & 0,039 \\
\hline
\end{tabular}

Nota. $F=5,113 ; p=0,007 ; R^{2}=0,052 ; R^{2}$ ajustado $=0,042$.

No segundo modelo foram escolhidas como variáveis independentes (preditoras) todos os fatores do IHS, todos os fatores do QEA e o resultado do escore total de Inteligência. A variável dependente foi o desempenho acadêmico, mensurado pelo coeficiente de rendimento (CR). Na primeira etapa foi incluída a variável Autoafirmação (IHS), sendo o modelo significativo com $R^{2}=0,147$. $\mathrm{Na}$ segunda etapa foi adicionada a variável Utilização de Recursos (QEA), o que proporcionou um aumento significativo de 0,057 no $R^{2}$. Na terceira etapa foi adicionada a variável Conversação (IHS), o que proporcionou um aumento significativo de 0,045 no $R^{2}$. As variáveis "Inteligência-Total", "Envolvimento Institucional", "Envolvimento Vocacional", "Envolvimento Social" e "Envolvimento Curricular", "Enfrentamento", "Auto-exposição" e "Autocontrole". Assim o modelo final pode ser observado na Tabela 5. 
Gomes, G. \& Soares, A. B. (2013). Inteligência, Habilidades Sociais e Expectativas Acadêmicas no Desempenho de Estudantes Universitários.

Tabela 5

Modelo 2 - Fatores de Expectativas Acadêmicas e Fatores de Habilidades Sociais como Preditores do Desempenho Acadêmico (CR)

\begin{tabular}{|c|c|c|c|c|}
\hline \multirow{2}{*}{ Modelo } & \multicolumn{2}{|c|}{ Coeficientes } & \multirow[t]{2}{*}{$t$} & \multirow[t]{2}{*}{$p$} \\
\hline & $B$ & Erro Padrão & & \\
\hline Constante & 8,51 & 0,47 & 18,08 & 0,001 \\
\hline IHS: Autoafirmação & 0,17 & 0,03 & 5,38 & 0,001 \\
\hline QEA: Utilização de Recursos & $-0,38$ & 0,11 & $-3,39$ & 0,001 \\
\hline IHS: Conversação & $-0,12$ & 0,03 & $-3,31$ & 0,001 \\
\hline
\end{tabular}

Nota. $F=20,299 ; p<0,001 ; R^{2}=0,249 ; R^{2}$ ajustado $=0,236$.

\section{Discussão e Considerações Finais}

Apesar das limitações da pesquisa em relação ao pequeno número de participantes, o estudo almejou colaborar na melhora do entendimento sobre o que pode interferir no desempenho acadêmico do estudante. Desse modo, o estudo constatou que as expectativas acadêmicas e as habilidades sociais podem influenciar no desempenho acadêmico do estudante e que, no entanto, a inteligência fluida não se apresentou como determinante nos resultados de avaliação acadêmica.

Em relação às Habilidades sociais, as de enfrentamento, de autoafirmação e de autocontrole da agressividade podem interferir de modo positivo no desempenho do estudante. Conforme verificado por Contreras et al. (2008), Del Prette e Del Prette (2001a), Feitosa et al. (2009) e Furtado et al. (2003), foi também constatada a relação existente entre comportamentos avaliados como habilidosos socialmente, em especial os assertivos e o rendimento escolar de alunos de diversas nacionalidades e várias escolas de Portugal. Porém, as habilidades sociais de conversação influenciam de modo negativo no rendimento acadêmico, resultado este que pode demonstrar que os estudantes com mais habilidades de conversação utilizam esses recursos visando construir amizades com seus pares com intuito de obter suporte tanto social quanto emocional em detrimento da busca efetiva de resultados acadêmicos mais substantivos (Fernandes, \& Almeida, 2005; Teixeira, Dias, Wottrich, \& Oliveira, 2008).

No que se refere a expectativas acadêmicas o estudo apontou que $\mathrm{o}$ aluno com mais expectativas sobre o envolvimento institucional e sobre a utilização de recursos tem desempenho inferior. Porém, o aluno que tem mais expectativas em relação ao envolvimento curricular e vocacional tem seu desempenho aumentado. Aparentemente quando os alunos iniciantes depositam credibilidade em seus recursos pessoais, em detrimento aos recursos institucionais e ambientais, que possivelmente ainda não os conhecem o suficiente, se percebem mais seguros e confiantes para obter melhores resultados, o que pode estar associado às expectativas mais realistas e fundamentadas sobre os seus recursos pessoais, e também à responsabilidade por conduzi-lo a se envolver com tarefas compatíveis com seus interesses no Ensino Superior (Kuh, Gonyea, \& Willians, 2005). O mesmo resultado foi verificado por Fernandes e Almeida (2005), que observaram que os alunos no início do curso apresentam maiores níveis de expectativas irrealistas e, assim, resultam em menor desempenho acadêmico, por induzirem os alunos a se interessarem por tarefas conflitantes com os seus objetivos acadêmicos. Por outro lado, os alunos com melhor desempenho voltaram seus interesses para área vocacional demonstrando confiança em sua opção de estudo.

No tocante a inteligência, o mesmo resultado foi encontrado no estudo de Maia e Fonseca (2002) que, embora com uma amostra de alunos do Ensino Fundamental com idade entre 7 e 15 anos, não encontraram correlação entre o Quociente de Inteligência de estudantes e o rendimento escolar. Da mesma forma, os resultados da pesquisa de Almeida et al. (2008) constataram em 4.899 estudantes portugueses do $5^{\circ}$ ao $12^{\circ}$ ano que as correlações entre a inteligência e o rendimento escolar diminuem ao longo da formação acadêmica. Assim, outras capacidades podem ser exigidas do aluno inteligente no decorrer de sua formação para que consiga superar as dificuldades iniciais do curso superior.

A presente pesquisa também mostrou que existe correlação entre expectativas acadêmicas e habilidades sociais. Assim, estudantes com maiores escores de habilidades sociais têm mais expectativas sobre o envolvimento vocacional, o envolvimento curricular e o envolvimento social. Quando se analisa separadamente os fatores das habilidades sociais observa-se que os alunos com capacidade de enfrentamento apresentaram mais expectativas em relação ao que envolve sua vocação. Porém, possuem menos expectativas sobre a infraestrutura da instituição e nos equipamentos por esta disponibilizados. Quanto aos alunos com capacidades para se autoexporem socialmente, são os que têm mais expectativas sobre a infraestrutura da instituição, a utilização de seus equipamentos e o envolvimento social com professores e alunos. Enquanto os alunos que possuem um bom autocontrole possuem menos expectativas quanto ao envolvimento vocacional, envolvimento social e a utilização de recursos. Aparentemente, os alunos depositam mais expectativas nos recursos que acreditam acrescentar valores a suas habilidades pessoais 
existentes na tentativa de potencializá-los e menos expectativas nos que eles percebem dificuldades em processar, com o intuito de melhorar o seu desempenho acadêmico no início do curso. As correlações entre as dimensões das expectativas acadêmicas, os fatores das habilidades sociais e da inteligência fluida podem ser entendidos, conforme Fernandes e Almeida (2005), que verificaram nos alunos com melhor rendimento ao ingressar no curso superior, em oposição aos com baixo rendimento acadêmico, a presença de expectativas mais realistas em relação aos seus recursos pessoais, às oportunidades, características e demandas do ambiente acadêmico.

O estudo não observou correlação entre habilidades sociais e inteligência, mesmo resultado verificado por Oliveira (2004), ao pesquisar 218 estudantes universitários com idade entre 17 e 56 anos, que averiguou a inexistência de correlação entre inteligência e habilidades sociais, e o de Cunha (2004) com 99 alunos do Instituto Militar de Engenharia que, da mesma forma, não encontrou correlação entre habilidades sociais e inteligência.

Considerando que os alunos utilizam suas habilidades pessoais com o objetivo de atingirem melhor desempenho acadêmico e para se motivarem a dar continuidade ao curso escolhido, as instituições de ensino deveriam conhecer melhor e avaliar as expectativas dos estudantes sobre o Ensino Superior com o objetivo de torna-las mais compatíveis com a realidade do campus universitário. Dessa forma, abririam a possibilidade de criar ambientes universitários mais acolhedores das necessidades iniciais do estudante diminuindo o impacto de suas dificuldades iniciais e consequentemente em sua decisão em dar continuidade ao curso escolhido. Assim, tanto a instituição de Ensino Superior quanto os alunos poderiam assumir as suas reais responsabilidades em relação aos índices de evasão escolar e consequentemente aos custos financeiros e sociais provocados por ela.

\section{Referências}

Almeida, L. S., Ferreira, A. L., \& Guisande, M. A. (2009). Inteligência: Perspectivas teóricas. Coimbra, Portugal: Almedina.

Almeida, L. S., Gonçalves, A., Salgueira, A. P., Soares, A. P., Machado, C., Machado, J. C., ...Vasconcelos, R. (2003). Expectativa de envolvimento acadêmico à entrada da Universidade: Estudo com alunos da Universidade do Minho. Psicologia: Teoria Investigação e Prática, 8(1), 3-15.

Almeida, L. S., Guisande, M., \& Primi, R. (2008). Construto e medida da inteligência: Contributos da abordagem fatorial. In L. S. Almeida, M. A. Guisande, \& R. Primi (Eds.), Inteligência: Definição e medida na confluência de múltiplas concepções (pp. 1-20). São Paulo, SP: Casa do Psicólogo.

Almeida, L. S., \& Primi, R. (2000). Estudo de validação da Bateria de Provas de Raciocínio (BPR-5). Psicologia: Teoria e Pesquisa, 6(2), 165-173.

Baptista, M. N., Amadio, A., Rodrigues, E. C., Santos, K. M., \& Palludetti, S. A. T. (2004). Avaliação dos hábitos, conhecimento e expectativas de alunos de um curso de Psicologia. Psicologia Escolar e Educacional, 8(2), 207-217.
Bariani, I. C. D., \& Pavani, R. (2008). Sala de aula na universidade: Espaço de relações interpessoais e participação acadêmica. Estudos de Psicologia (Campinas), 25(1), 67-75.

Braga, M. M., Miranda-Pinto, C. O. B., \& Cardeal, Z. L. (1997). Perfil socioeconômico dos alunos, repetência e evasão no curso de química da UFMG. Química Nova, 20(4), 438-444.

Bremer, C. D., \& Smith, J. (2004). Teaching social skills. Information Brief, 3(5), 1-5.

Caballo, V. E. (2003). Manual de avaliação e treinamento das habilidades sociais. São Paulo, SP: Santos.

Carrara, K., \& Betetto, M. F. (2009). Formação ética para a cidadania: Uma investigação de habilidades sociais medidas pelo inventário de habilidades sociais. Estudos de Psicologia (Campinas), 26(3), 337-347.

Contreras, K., Caballero, C., Palácio, J., \& Pérez, A. (2008). Factores asociados al fracaso académico en estudiantes universitarios de Barranquilla (Colombia). Psicología desde el Caribe, (22), 110-135.

Cunha, M. S., \& Carrilho, D. M. (2005). O processo de adaptação ao Ensino Superior e o rendimento acadêmico. Psicologia Escolar e Educacional, 9(2), 215-224.

Cunha, S. M. (2004). A inteligência e as habilidades sociais na adaptação de alunos ao curso superior: Um estudo com alunos do $1^{\circ}$ ano do Instituto Militar de Engenharia (Dissertação de mestrado, Universidade Gama Filho, Rio de Janeiro, RJ, Brasil).

Del Prette, A., \& Del Prette, Z. A. P. (1999). Psicologia das habilidades sociais: Terapia e educação (2. ed.). Petrópolis, RJ: Vozes.

Del Prette, A., \& Del Prette, Z. A. P. (2001a). Psicologia das relações interpessoais - Vivências para o trabalho em grupo (3. ed.). Petrópolis, RJ: Vozes.

Del Prette, A., \& Del Prette, Z. A. P. (2001b). Inventário de Habilidades Sociais - IHS. São Paulo, SP: Casa do Psicólogo.

Feitosa, F. B., Matos, M. G., Del Prette, Z. A. P., \& Del Prette, A. (2009). Desempenho acadêmico e interpessoal em adolescentes portugueses. Psicologia em Estudo, 14(2), 259-266.

Fernandes, E. P., \& Almeida, L. S. (2005). Expectativas e vivências acadêmicas: Impacto no rendimento dos alunos do $1^{\circ}$ ano. Psychologia, 40(1), 267-278.

Ferreira, A. J., Almeida, L. S., \& Soares, A. P. C. (2001). Adaptação acadêmica em estudante do $1^{\circ}$ ano: Diferenças de gênero, situação de estudante de curso. PsicoUSF, 6(1), 1-10.

Flores, A. C., \& Lever, J. P. (2008). El processo de admisión como predictor del rendimento académico em la educación superior. Universitas Psychologica, 7(1), 197-213.

Furtado, E. S., Falcone, E. M. O., \& Clark, C. (2003). Avaliação do estresse e das habilidades sociais na experiência acadêmica de estudantes de Medicina de uma universidade do Rio de Janeiro. Interação em Psicologia, 7(2), 43-51.

Haward, J. A. (2005). Why should we care about student expectations? In T. E. Miller, B. E. Bender, \& J. H. Schuh (Eds.), Promoting reasonable expectations: Aligning student and institutional views of college experience (pp. 10-32). San Francisco, CA: Jossey-Bass.

Igue, E. A., Bariani, I. C. D., \& Milanese, P. V. B. (2008). Vivências acadêmicas e expectativas de universitários ingressantes e concluintes. PsicoUSF, 13(2), 155-164.

Kuh, G. D., Goneya, R. M., \& Willians, J. M. (2005). What students expect from college and what they get. In T. E. Miller, B. E. Bender, \& J. H. Schuh, Promoting reasonable expections: Aligning student and instituitional views of the college experience (pp. 34-61). San Francisco, CA: Jossey-Bass. 
Gomes, G. \& Soares, A. B. (2013). Inteligência, Habilidades Sociais e Expectativas Acadêmicas no Desempenho de Estudantes Universitários.

Maia, A. C. B., \& Fonseca, M. L. (2002). Quociente de inteligência e aquisição de leitura: Um estudo correlacional. Psicologia: Reflexão e Crítica, 15(2), 261-270.

Miller, T. E. (2005). Introdution. In B. E. Miller, B. E. Bender, \& J. H. Schuh, Promoting reasonable expections: Aligining student and instituitional views of the college experience (pp. 1-9). San Francisco, CA: Jossey-Bass.

Nogueira, F. (2011). Vestibular e educação. G1. Recuperado em 6 de setembro, 2011, de http://g1.globo.com/vestibulare-educacao/noticia/2011/02/pais-perde-r-9-bilhoes-comevasao-no-ensino-superior-diz-pesquisador.html

Oliveira, P. R. (2004). Inteligência fluida, inteligência cristalizada e habilidades sociais: Um estudo multicorrelacional (Dissertação de mestrado, Universidade Gama Filho, Rio de Janeiro, RJ, Brasil).

Pascarella, E. T., \& Terenzini, P. T. (2005). How college affects students. A third decade of research. Los Angeles, CA: Jossey-Bass.

Primi, R., Santos, A. A. A., \& Vendramini, C. M. (2002). Habilidades básicas e desempenho acadêmico em universitários ingressantes. Estudos de Psicologia (Natal), 7(1), 47-55.

Primi, R., Santos, A. A. A., Vendramini, C. M., Taxa, F., Muller, F. A., Lakjanenko, M. F., \& Sampaio, I. S. (2001). Competências e habilidades cognitivas: Diferentes definições dos mesmos constructos. Psicologia: Teoria e Pesquisa, 17(2), 151-159.

Soares, A. P. C., \& Almeida, L. S. (2007). Questionário de Envolvimento Acadêmico. In M. R. Simões, C. Machado, M. M. Gonçalves, \& L. S. Almeida (Eds.), Avaliação psicológica: Instrumentos validados para a população portuguesa: Vol. III (pp. 149-167). Coimbra, Portugal: Quarteto.

Teixeira, M. A. P., Dias, A. C. G., Wottrich, S. H., \& Oliveira, A. M. (2008). Adaptação à Universidade em jovens calouros. Psicologia Escolar e Educacional, 12(1), 158-202.

Terenzini, P. T., Springer, L., Pascarella, E. T., \& Nora, A. (1995). Influences affecting the development of students' critical thinking skills. Research in Higher Education, 36(1), 23-39. 